\title{
AVAliAÇÃo DA PROTEÓlise E DO DERRETIMENTO DO gUEIJO PRATO OBTIDO POR ULTRAFILTRAÇÃO ${ }^{1}$
}

\author{
Agnes NARIMATSU², José Raimundo F. DORNELLAS ${ }^{2}$, Leila M. SPADOTI², Patrícia D. PIZAIA²,
}

\author{
Salvador M. ROIG ${ }^{2, *}$
}

\section{RESUMO}

O queijo Prato é o segundo tipo de queijo mais consumido no Brasil. A aplicação da ultrafiltração (UF) do leite é uma das alternativas de processos de fabricação de queijos que tem despertado interesse do setor laticinista, porém, tem-se observado uma menor taxa de maturação nos queijos semi-duros, como o queijo prato, obtidos por UF. Neste trabalho foram feitos três ensaios de produção de queijo Prato, com três tratamentos cada, respectivamente, com: leite não concentrado (Trat. 1) e leite concentrado por UF até as relações de concentração volumétrica (RCV) de 2,5:1 e 3,7:1 (Trat. 2 e Trat. 3, respectivamente). Os queijos foram fabricados pelo processo tradicional com coagulação enzimática (coalho de vitelo Bela Vista ${ }^{\oplus}-90 \%$ de quimosina) (quarenta minutos $/ 35^{\circ} \mathrm{C}$ ), corte de grão 1 , remoção parcial de $20 \%$ de soro e cozimento direto por adição de água a $80^{\circ} \mathrm{C}$ até o ponto da massa, enformagem, prensagem e cura a $7^{\circ} \mathrm{C}$. Os três tratamentos foram comparados entre si com relação à composição centesimal, derretimento e proteólise. Em relação à composição, os queijos obtidos por UF apresentaram maiores porcentagens de acidez, umidade e proteina e menor teor de gordura. Observou-se, no Tratamento 3, uma capacidade de derretimento maior e uma proteólise mais intensa, bem como o seu aumento em função do tempo. Palavras-chave: queijo Prato; concentração; maturação; derretimento.

\section{SUMMARY}

PROTEOLYSIS AND MELTING EVALUATION ON PRATO CHEESE OBTAINED BY ULTRAFILTRATION. Prato cheese is the second most consumed cheese in Brazil. Milk ultrafiltration (UF) is one of the processing alternatives for cheese manufacture which is receiving increased interest of the dairy sector, however, a lower rate of maturation in semi-hard cheeses made by UF has been reported. On this study were realized three processing experiments with three treatments each, respectively: with non concentrated milk (Trat. 1) and with milk concentrated by UF up to volumetric concentration ratios (RCV) of 2.5:1 and 3.7:1 (Trat. 2 and Trat. 3, respectively). The cheeses were manufactured by the traditional process with enzymatic coagulation (calf rennet Bela Vista ${ }^{\circledR}-90 \%$ quimosin) forty minutes $/ 35^{\circ} \mathrm{C}$ ), cut size one, partial remotion of $20 \%$ of whey and direct cooking by addition of water at $80^{\circ} \mathrm{C}$, molding, pressing and ripening at $7{ }^{\circ} \mathrm{C}$. The three treatmens were compared among them with respect to composition, melting and proteolysis. With respect to composition, cheeses made by UF presented larger acidity, moisture and total protein and lower fat content. It was observed on treatment 3 a larger melting capacity and more intense proteolysis, as also their increase with respect to time.

Keywords: Prato cheese; concentration; ripening; melting.

\section{1 - INTRODUÇÃO}

O queijo Prato, de origem dinamarquesa, é semelhante ao Gouda e Danbo, porém com sabor e textura próprios. Possui ampla distribuição no Brasil e, junto com os queijos Mussarela, Minas, Requeijão e Parmesão, é um dos queijos mais consumidos no país. Sua produção média anual é de 70.000ton. [5] e inclui as variedades Lanche, Cobocó e Estepe, que diferem quanto ao formato e ao peso [14, 29].

A tecnologia da ultrafiltração (UF) consiste na concentração de um meio fluído, como o leite, quando este é forçado a fluir, sob pressão, sobre a superficie de uma membrana semipermeável [9]. A utilização de tal processo na fabricação de queijos foi proposta por MAUBOIS, MOCQUOT e VASSAL [25] e a fabricação com sucesso, de alguns tipos de queijo como Camembert, Saint-Paulin, Quark, Queso Blanco e queijos moles coagulados por renina, tem sido descrita na literatura $[7,8,18,24,26]$. Dentre as vantagens atribuídas ao uso de UF na fabricação de queijos está o aumento do

${ }^{1}$ Recebido para publicação em 17/10/2002. Aceito para publicação em 22/07/2003 (001004).

${ }^{2}$ Faculdade de Engenharia de Alimentos, Universidade Estadual de Campinas-UNICAMP. CEP: 13083-970-Campinas-SP, Brasil. E-mail: salvador@fea.unicamp.br

* A quem a correspondência deve ser enviada. rendimento, a fabricação continua e automatizada, a economia de mão-de-obra e ingredientes e a produção de soro com menor poder poluente [20]. Entretanto, a produção de queijos semiduros e duros, a partir de leite ultrafiltrado, tem apresentado alguns problemas como deficiências no sabor, aroma e textura. Umas das prováveis razões para tal limitação é a menor taxa de maturação encontrada nesses queijos [17].

A maturação é caracterizada pela quebra das proteínas do queijo (caseínas), resultante da atividade de várias enzimas. Os principais contribuintes são o coalho, proteases e peptidases do fermento lático e/ou flora secundária e enzimas naturais do leite [12]. Durante a proteólise ocorre uma fragilização da rede protéica do queijo [21], aumentando a capacidade de derretimento do mesmo [32]. Essa propriedade é importante para o queijo Prato, uma vez que a aceitabilidade do consumidor a este produto está relacionada com características físico-quimicas, sensoriais e funcionais adequadas [28].

A atividade proteolitica em queijos é principalmente determinada pelos niveis presentes de coalho residual e enzimas nativas do leite, pela relação sal na umidade, pela temperatura de maturação, tipo de coagulante usado e mudanças no $\mathrm{pH}$ durante a maturação [21]. No caso da relação sal na umidade, quanto maior este valor, menor é a proteólise [21]. 
Dada a importância do queijo Prato no Brasil, a possibilidade de fabricação do queijo a partir de UF e o derretimento como característica desejável no produto, quando o mesmo é utilizado em lanches e afins. Este trabalho avaliou a propriedade de derretimento ao longo da maturação de queijos Prato obtidos por UF em diferentes RCVs $(2,5: 1$ e 3,7:1) e comparou-se os resultados obtidos com os de um queijo Prato padrão, fabricado tradicionalmente.

\section{2 - MATERIAL E MÉTODOS}

Foram realizados três experimentos com três tratamentos cada, respectivamente: Tratamento 1 (com leite não concentrado por ultrafiltração); Tratamento 2 (com leite concentrado por ultrafiltração até RCV de 2,5:1) e Tratamento 3 (com leite concentrado por ultrafiltração até RCV de 3,7:1).

\section{1 - Fabricação de queijo}

\subsection{1 - Fabricação de queijo padrão}

A tecnologia de fabricação foi a tradicional, conforme técnica do Instituto de Laticínios Cândido Tostes [30], com adição de $\mathrm{CaCl}_{2}$ (50\%) na proporção de $50 \mathrm{~mL}$ para cada 100 litros de leite. O leite foi coagulado com a utilização de coalho de vitelo marca Bela Vista ${ }^{\circledR}(90 \%$ de quimosina) em quantidade suficiente para coagular o leite em 40 minutos à temperatura de $35^{\circ} \mathrm{C}$. Foi utilizada cultura lática mesófila (G3 MIX 6-VISBYVAC ${ }^{\circledR}$-B50, composta de múltiplas cepas mistas de Lactococcus lactis subsp. lactis e Lactococcus lactis subsp. cremoris) liofilizada concentrada, de utilização direta no tanque, na quantidade de $10 \%$ da recomendada pelo fabricante.

\subsection{2 - Concentração do leite por ultrafiltração}

O leite foi concentrado por ultrafiltração, em batelada, com módulo de membranas minerais de 20.000 Daltons, TECH - SP, modelo S 37, com pressão de entrada de $2,5 \mathrm{~kg} / \mathrm{cm}^{2}$ e pressão de saída de $1,5 \mathrm{~kg} / \mathrm{cm}^{2}$, à temperatura de $55^{\circ} \mathrm{C}$ até atingir as RCVs desejadas, quando, então, foi retirado o volume de retentado necessário a cada tratamento.

A RCV dos retentados foi calculada segundo a equação (1), com base no fator de concentração de gordura, uma vez que é o único componente do leite totalmente retido pela membrana.

$\mathrm{RCV}=\frac{\text { Teor de gordura no retentado }(\%)}{\text { Teor de gordura no leite }(\%)}$

\subsection{3 - Fabricação de queijo a partir de leite ultrafiltrado}

O retentado foi coagulado a $35^{\circ} \mathrm{C}$, com utilização do mesmo coalho e da mesma cultura lática utilizada para o queijo padrão, adaptando-se a técnica adotada para o queijo padrão. Utilizou-se cultura lática e agente coagulante na mesma proporção que seria necessária para o leite equivalente ao leite concentrado. Contudo, foram modificados os tempos de mexedura, pré-cozimento e ponto da massa, uma vez que parte da umidade a ser extraída dos grãos, nos referidos tratamentos, foi retirada no processo de ultrafiltração.

\section{2 - Métodos analíticos}

\subsection{1 - Análise centesimal dos queijos}

A análise centesimal foi feita nos queijos com 10 dias de armazenagem. A acidez titulável foi realizada conforme adaptação da metodologia da AOAC 920.124 [1] e o pH foi medido através de leitura direta em peagômetro, modelo Digimed DM-20. As cinzas foram determinadas conforme AOAC, metodologia 935.42 [1], o extrato seco total (E.S.T.), de acordo com a AOAC, metodologia 925.23 [1] e a umidade calculada pela equação:

$\mathrm{U}(\%)=100 \%$ - E.S.T $(\%)$

O sal foi determinado pelo método de Volhard modificado, conforme BARBANO, LYNCH \& FLEMING [2] e o teor de sal na umidade (S/U) foi calculado de acordo com a equação:

$\mathrm{S} / \mathrm{U}(\%)=\frac{\mathrm{Sal}(\%)}{\mathrm{Sal}(\%)+\mathrm{U}(\%)} \times 100 \%$

A determinação do teor de NT foi realizada pelo método Kjeldahl, conforme metodologia da AOAC 991.20 [1]. A proteina total (PT) foi calculada pela multiplicação da porcentagem de NT por 6,38. O teor de nitrogênio não caséico (solúvel em $\mathrm{pH} 4,6$ ) foi determinado segundo BARBANO, LYNCH \& FLEMING [2] e de nitrogênio não protéico (solúvel em TCA 12\%), segundo AOAC $991.21[1]$.

A determinação de gordura foi feita pelo método de Gerber [3] e o teor de gordura no extrato seco (G.E.S.) calculado segundo a equação:

G.E.S. $(\%)=\frac{\text { Gordura }(\%)}{\text { E.S.T }(\%)} \times 100 \%$

Todas as análises foram realizadas em triplicata.

\subsection{2 - Determinação da proteólise}

A proteólise nos queijos foi avaliada com base nos indices de extensão (IEP) e profundidade (IPP) de proteólise (Equações 5 e 6 respectivamente), com 10, 25 e 45 dias de estocagem.

$\operatorname{IEP}(\%)=\frac{\text { Nitrogênio não caséico(\%) }}{\text { Nitrogênio total }(\%)} \times 100 \%$
$\operatorname{IPP}(\%)=\frac{\text { Nitrogênio não protéico(\%) }}{\text { Nitrogênio total }(\%)} \times 100 \%$ 


\subsection{3 - Determinação da capacidade de derreti- mento}

A capacidade de derretimento foi determinada pelo método modificado de Schreiber, conforme descrito por KOSIKOWSKI [19], sendo realizada em quadruplicata nos queijos com 10, 25 e 45 dias de armazenamento.

O teste consistiu em retirar, da peça de queijo, um cilindro de $36 \mathrm{~mm}$ de diâmetro. Com o auxílio de um fatiador, foram obtidos discos com $7 \mathrm{~mm}$ de espessura. Foram utilizadas quatro fatias, obtidas da região mais interna da peça, sendo cada uma colocada no centro de uma placa de Petri, devidamente dividida em 8 áreas iguais através de diâmetros. Foram medidos 4 diâmetros da cada amostra $\left(D_{i}\right)$ e, então, as placas com as amostras foram dispostas em uma estufa a $107^{\circ} \mathrm{C}$ por 7 minutos, de acordo com a Figura 1. Posteriormente, as placas foram deixadas por 30 minutos a temperatura ambiente e os diâmetros de cada amostra derretida foram medidos novamente $\left(\mathrm{D}_{\mathrm{f}}\right)$.

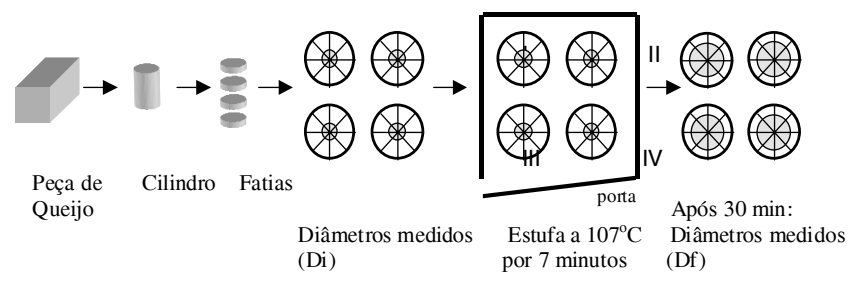

FIGURA 1. Esquema da análise de derretimento.

A capacidade de derretimento foi calculada usando a seguinte equação:

$\mathrm{CD}(\%)=\frac{\mathrm{D}_{\mathrm{f}}{ }^{2}-\mathrm{D}_{\mathrm{i}}{ }^{2}}{\mathrm{D}_{\mathrm{i}}{ }^{2}} \times 100 \%$

\section{3 - Delineamento experimental e análise estatística}

O delineamento estatístico adotado para o experimento foi Split-plot em blocos, onde as parcelas foram os tratamentos, a sub-parcela, o tempo e o bloco, a batelada de leite a ser processada. Foram utilizadas três bateladas, uma para cada réplica completa, formando três blocos.

Foram avaliados tratamentos formados por: Trat. 1: Sem Ultrafiltração; Trat. 2: Ultrafiltração até $\mathrm{RCV}=2,5: 1$ e Trat. 3: Ultrafiltração até $\mathrm{RCV}=4: 1$. A composição dos queijos resultantes dos três tratamentos foi estatisticamente comparada através de análise de variância, utilizando-se procedimento de comparação múltipla entre pares de médias, no décimo dia após a produção. As análises de proteólise e de derretimento foram avaliadas através de análise de variância, utilizando-se do procedimento de comparação múltipla entre pares de médias com 10, 25 e 45 dias de fabricação. Todos os cálculos foram realizados com auxílio do pro-

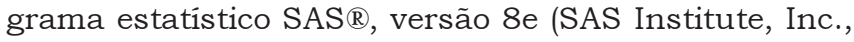
Cary, NC.).

\section{3 - RESULTADOS E DISCUSSÃO}

\section{1- Composição média dos queijos dos diferentes tratamentos}

Os tratamentos apresentaram diferenças significativas em algumas variáveis, conforme mostrado na $\mathrm{Ta}$ bela 1.

A acidez titulável aumentou com o uso de leite UF, principalmente o de $\mathrm{RCV}$ de 3,7:1, resultado esse compativel com as informações feitas por EL-GAZZAR \& MARTH [10], segundo a qual o leite UF é um meio mais favorável que o leite normal para o crescimento da cultura lática, o que faz com que o crescimento e a produção de ácido, por Lactococcus lactis subsp. lactis e Lactococcus lactis subsp. Cremoris, aumentem com a concentração do leite.

O teor de cinzas não apresentou diferenças significativas entre os tratamentos $(p=0,1461)$, porém os teores de umidade e Extrato Seco Total (EST) apresentaram. Os queijos elaborados a partir de leite UF apresentaram maior teor de umidade, possivelmente em decorrência de maior presença de soroproteinas desnaturadas, as quais tendem a aumentar a capacidade de retenção de água do queijo.

Não houve diferença significativa entre os tratamentos com relação ao teor de sal $(p=0,0489)$, mas houve com relação ao teor de sal/ umidade $(\mathrm{p}=0,0007)$. A diferença com relação ao teor de sal/umidade ocorreu em decorrência da menor porcentagem de umidade apresentada pelo queijo padrão.

TABELA 1. Composição média $(n=3)$ dos queijos elaborados com leite não concentrado (Tratamento 1) e com leite concentrado, por ultrafiltração, até as relações de concentração volumétrica de 2,5:1 e 3,7:1 (Tratamentos 2 e 3, respectivamente), com 10 dias de estocagem.

\begin{tabular}{lccc}
\hline Componente & \multicolumn{3}{c}{ Tratamentos } \\
\cline { 2 - 4 } & 1 & 2 & 3 \\
\hline Acidez (\%) & $0,57^{\mathrm{c}}$ & $0,59^{\mathrm{b}}$ & $0,71^{\mathrm{a}}$ \\
pH & $5,41^{\mathrm{b}}$ & $5,45^{\mathrm{a}}$ & $5,37^{\mathrm{c}}$ \\
Cinzas (\%) & $3,73^{\mathrm{a}}$ & $4,08^{\mathrm{a}}$ & $4,03^{\mathrm{a}}$ \\
E.S.T. (\%) & $51,6^{\mathrm{a}}$ & $48,35^{\mathrm{c}}$ & $48,77^{\mathrm{b}}$ \\
Umidade (\%) & $48,4^{\mathrm{c}}$ & $51,65^{\mathrm{a}}$ & $51,23^{\mathrm{b}}$ \\
Sal (\%) & $1,63^{\mathrm{a}}$ & $1,67^{\mathrm{a}}$ & $1,67^{\mathrm{a}}$ \\
Gordura (\%) & $24,89^{\mathrm{a}}$ & $20,44^{\mathrm{b}}$ & $20,84^{\mathrm{b}}$ \\
Proteína (\%) & $18,16^{\mathrm{c}}$ & $19,34^{\mathrm{b}}$ & $21,38^{\mathrm{a}}$ \\
S/U (\%) & $3,27^{\mathrm{a}}$ & $3,14^{\mathrm{b}}$ & $3,16^{\mathrm{b}}$ \\
G.B.S. (\%) & $48,30^{\mathrm{a}}$ & $42,32^{\mathrm{b}}$ & $42,61^{\mathrm{b}}$ \\
\hline
\end{tabular}

Obs: Médias com a mesma letra na mesma linha não são significativamente diferentes $(p>0,05)$

Os tratamentos diferiram significativamente com relação ao teor de gordura ( $\mathrm{p}<0,0001)$. Os dados do Tabela 1 mostraram que o queijo padrão recuperou mais gordura, seguido dos queijos dos tratamentos 3 e 2 , respectivamente. Tal fato ocorreu, provavelmente, pelos danos causados aos glóbulos de gordura durante o processo de ultrafiltração, devido à operação de bombeamento e à turbulência na linha. 
Quanto ao teor de proteína, os tratamentos apresentaram diferença significativa quando comparados entre si $(\mathrm{p}<0,0001)$. O uso de leite UF tende a aumentar o teor de proteina no queijo, devido à incorporação de soroproteinas [22], sendo que quanto maior a RCV do leite UF maior tende a ser essa incorporação.

\section{2 - Índices de proteólise}

A proteólise é indicada pelo aumento dos indices de extensão e profundidade no decorrer do tempo. O indice de extensão está fundamentalmente relacionado com as proteinases naturais do leite e do agente coagulante, as quais degradam a proteina em peptídeos de alto peso molecular. $O$ indice de profundidade de proteólise está relacionado principalmente com a atividade das endoenzimas e exoenzimas da cultura lática empregada na fabricação do queijo e de possiveis contaminantes, que degradam os peptídeos de alto peso molecular a peptídeos de baixo peso molecular. No entanto, não há uma divisão precisa onde começa um indice e termina o outro.

Neste estudo o indice de extensão de proteólise apresentou diferença significativa entre os tratamentos $(p=0,0039)$. O tratamento 3 foi significativamente diferente do 1 , o qual não diferiu significativamente do 2. Todos eles sofreram influência do fator tempo ( $\mathrm{p}<0,0001)$, conforme observado na Figura 2.

$\mathrm{O}$ indice de profundidade de maturação também apresentou diferença significativa entre os tratamentos $(\mathrm{p}=0,0011)$, com o 3 diferindo significativamente do 1 e do 2 , e na variável tempo ( $\mathrm{p}<0,001)$, o que comprova as diferenças dos tratamentos ao longo do tempo, como observado na Figura 3.

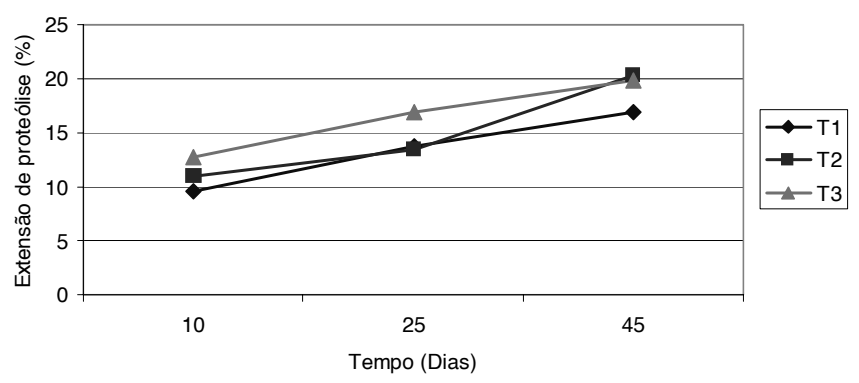

FIGURA 2. Índice de extensão de proteólise dos queijos elaborados com leite não concentrado (Tratamento 1) e com leite concentrado, por ultrafiltração, até as relações de concentração volumétrica de 2,5:1 e 3,7:1 (Tratamentos 2 e 3, respectivamente), durante 45 dias de estocagem refrigerada.

Os resultados obtidos neste trabalho indicam que a proteólise tende a ser maior quanto maior é o fator de concentração do retentado. SPANGLER et al. [31] utilizaram quantidades de coalho baseado no volume de leite não concentrado para a fabricação de queijo tipo Gouda e encontraram, nos queijos obtidos por ultrafiltração, maiores indices de proteólise do que no queijo convencional. Segundo esses autores, provavel- mente, maior quantidade de coalho foi retida nos queijos produzidos pelos retentados de maior concentração, uma vez que houve menor sinérese do soro nestes queijos. Neste trabalho, a quantidade de coalho utilizada também foi calculada baseada na quantidade de leite não concentrado e, da mesma forma, obteve-se menor quantidade de soro com o aumento da RCV do leite. CREAMER, IYER \& LELIEVRE [6] também mostraram que aumentando o coalho residual para niveis acima dos encontrados em queijos tradicionais, podese aumentar a taxa de proteólise. Ao contrário dos resultados do presente trabalho, GREEN [15] e GREEN et al. [16] mostraram que a proteólise tende a ser menor quando o fator de concentração do retentado é maior, contudo, nos trabalhos desenvolvidos por esses pesquisadores a quantidade de coalho utilizada foi reduzida quando a concentração do retentado aumentou, a fim de permanecer constante o tempo de corte da massa.

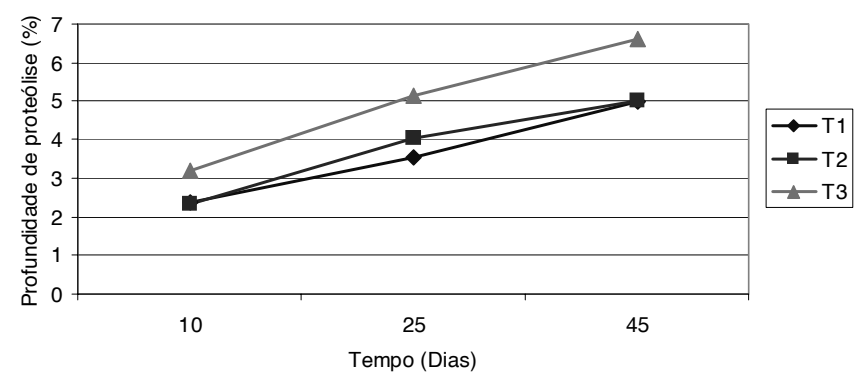

FIGURA 3. Índice de profundidade de proteólise dos queijos elaborados com leite não concentrado (Tratamento 1) e com leite concentrado, por ultrafiltração, até as relações de concentração volumétrica de 2,5:1 e 3,7:1 (Tratamentos 2 e 3 , respectivamente), durante 45 dias de estocagem refrigerada.

\section{3 - Acompanhamento do pH e acidez titulável}

Comparando os três diferentes tratamentos, observou-se um aumento de acidez (Figura 5) e uma diminuição do pH (Figura 4) ao longo do tempo, muito embora não houvesse diferença significativa para acidez $(\mathrm{p}=0,0552)$ e para os valores de $\mathrm{pH}(\mathrm{p}=0,2050)$.

O decréscimo nos valores de $\mathrm{pH}$ para todos os tratamentos, mostrado na Figura 4, é devido à fermentação da lactose do queijo, com a formação de ácido lático [13] e é importante para prevenir o crescimento de bactérias patogênicas [11]. Além disso, a variação de $\mathrm{pH}$ ao longo do tempo também depende da capacidade tamponante do queijo, devido à quantidade de proteinas e sais minerais presentes.

BYNUM \& BARBANO [4] fabricaram queijo a partir de retentado, adicionando quantidade de coalho baseado no volume original de leite não concentrado e também obtiveram, em queijos obtidos por ultrafiltração, maior acidez titulável do que nos queijos fabricados tradicionalmente e uma proteólise similar entre os queijos com até 3 meses de maturação. 


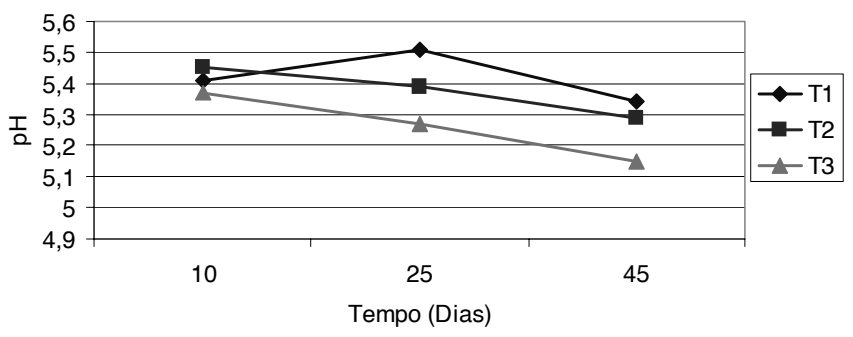

FIGURA 4. Avaliação do pH dos queijos elaborados com leite não concentrado (Tratamento 1) e com leite concentrado, por ultrafiltração, até as relações de concentração volumétrica de 2,5:1 e 3,7:1 (Tratamentos 2 e 3, respectivamente), durante 45 dias de estocagem refrigerada.

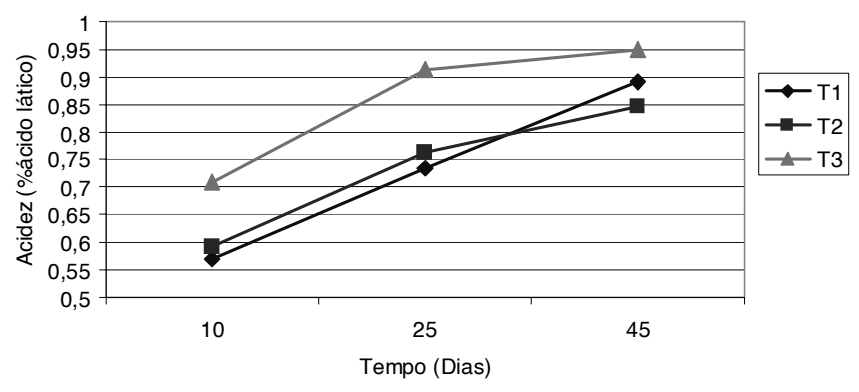

FIGURA 5. Avaliação da acidez dos queijos elaborados com leite não concentrado (Tratamento 1) e com leite concentrado, por ultrafiltração, até as relações de concentração volumétrica de 2,5:1 e 3,7:1 (Tratamentos 2 e 3, respectivamente), durante 45 dias de estocagem refrigerada.

\section{4 - Acompanhamento da capacidade de derreti- mento}

Com relação à capacidade de derretimento o tratamento 3 diferiu significativamente dos tratamentos 1 e 2 , os quais não diferiram entre si. Essa diferença de comportamento pode ser atribuída à diferença na proteólise. Sabe-se que o derretimento tende a ser maior quando a degradação de proteínas aumenta [27]. De fato, o queijo do tratamento 3 apresentou maior capacidade de derretimento (Figura 6), assim como maior proteólise (Figura 2).

A capacidade de derretimento aumentou significativamente ao longo do tempo ( $\mathrm{p}<0,0001)$ (Figura 6), assim como aumentou a proteólise (Figura 2).

Segundo a literatura, o queijo obtido por ultrafiltração tende a apresentar características de derretimento insatisfatórias e uma das causas pode ser a proteólise menos intensa em queijos obtidos por retentados [23]. Neste trabalho, nos queijos obtidos por ultrafiltração, foi observada uma maior proteólise, se comparada com a do queijo convencional, pelas razões discutidas anteriormente, e assim também apresentaram maior derretimento.

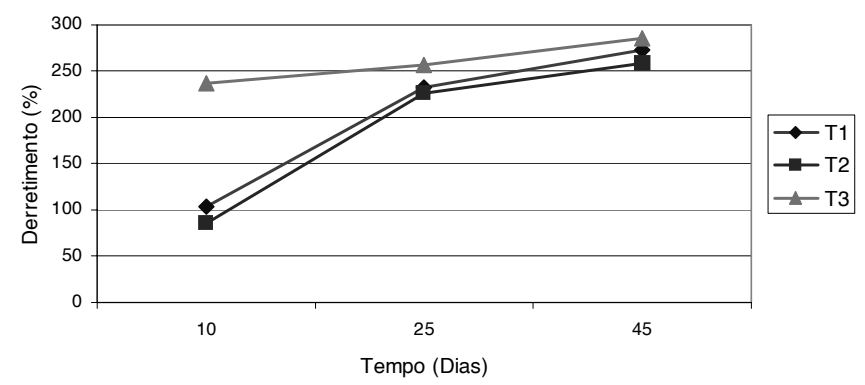

FIGURA 6. Avaliação da capacidade de derretimento dos queijos elaborados com leite não concentrado (Tratamento 1) e com leite concentrado, por ultrafiltração, até as relações de concentração volumétrica de 2,5:1 e 3,7:1 (Tratamentos 2 e 3 , respectivamente), durante 45 dias de estocagem refrigerada.

\section{4 - CONCLUSÕES}

Em relação à composição, os queijos obtidos por UF apresentaram maiores porcentagens de acidez, umidade e proteina e menor teor de gordura.

A proteólise e a capacidade de derretimento dos queijos elaborados com leite concentrado por ultrafiltração e com leite não concentrado aumentaram durante o período de estocagem (45 dias). Verificou-se que o uso de leite concentrado até a relação de concentração volumétrica de 3,7:1 resultou em queijos com valores de proteólise e capacidade de derretimento maiores do que os observados em queijos elaborados com leite concentrado até RCV igual a 2,5.

\section{5 - REFERÊNCIAS BIBLIOGRÁFICAS}

[1] AOAC - Association of Analytical Chemists. Official methods of analysis of AOAC international. $16^{\text {th }} \mathrm{ed}$. Washington: AOAC. 1995, 109p.

[2] BARBANO, D.M.; LYNCH, J.M.; FLEMING, J.R. Direct and indirect determination of true protein content of milk by Kjeldahl analysis: Collaborative study. Journal of Association of Official Analytical Chemists, v. 74, p. 281. 1991.

[3] BRITISH STANDARDS INSTITUTION. Determination of fat content of milk and milk products (Gerber Method). London: British Standards Institution. 1989, 12p.

[4] BYNUM, D.G.; BARBANO, D.M. Whole milk reverse osmosis retentates for Cheddar cheese manufacture: chemical changes during aging. Journal of Dairy Science, v. 68, p. 1-10. 1984.

[5] CICHOSCKI, A.J.; VAlduGA, E.; VAlduGA. A.T.; TORNADIJO, M.E.; FRESNO, J.M. Characterization of Prato Cheese, a Brazilian semi-hard cow variety: Evolution of physico-chemical parameters and mineral composition during ripening. Food Control, v. 13, n. 4-5, p. 329-336. 2002.

[6] CREAMER, L.K.; IYER, M.; LELIEVRE, J. Effect of various levels of rennet addition on characteristics of Cheddar cheese made from ultrafiltered milk. New Zealand Journal of Dairy Science and Technology, v. 22, n. 3, p. 205-214. 1987. 
[7] DELBEKE, R. Experiments on making Siant-Paulin by full concentration of milk with ultrafiltration. Milchwissenschaft, v.42, n. 4, p. 222-225. 1987.

[8] DUCRUeT, P.; MAUBOIS, J.L; GOUdECRANCHE, H.; PANNETIER, R. Elèments de fabrication de fromeges à pâte demi-dure et à ouverture propionique selon le procédé M.M.V. La Technique Laitiere, v. 957, p. 1316. 1981.

[9] DZIAZAK, J.D. Membrane separation technology offers processors unlimited potential. Food Technology, v. 44, n. 9, p. 108-113. 1990.

[10] EL-GAZZAR, F.E.; MARTH, E.H. Ultrafiltration and reverse osmosis in dairy technology: a review. Journal of Food Protection, v. 54, n. 10, p. 801-809. 1991.

[11] FARKYE, N. Y.; FOX, P. F. Objective indices of cheese ripening. Trends is Food Science \& Technology, p. 3740. 1990.

[12] FOX, P.F.; LAW, J. Enzimology of cheese ripening. Food Biotechnology, v. 5, n. 3, p. 239-262. 1991.

[13]FOX, P.F.; LUCEY, J.A.; COGAN, T.M. Glicolysis and related reaction during cheese manufacture and ripening. Critical reviews in food science and nutrition, v. 29, n. 4, p. 237-253, 1990.

[14] FURTADO, M.M. A arte e a ciência do queijo. 2a Edição. São Paulo: Globo. 1990, 297p.

[15] GREEN, M.L. Effect of milk pretreatment and making conditions on the properties of Cheddar cheese from milk concentrated by ultrafiltration. Journal of Dairy Research, v. 52, p. 555. 1985.

[16] GREEN, M.L.; GLOVER, F.A.; SCURLOCK, E.W.; MARSHALL, R.J.; HATFIELD, R.S. Effect of use of milk concentrated by ultrafiltration on the manufacture and ripening of Cheddar cheese. Journal of Dairy Research, v. 48, p. 333-341. 1981.

[17] GUINÉE, T.P.; PUDJA, P.D.; MULHOLLAND, E.O. Effect of milk protein standardization, by ultrafiltration, on the manufacture, composition and maturation of Cheddar cheese. Journal of Dairy Research, v. 61, p. 117-131. 1994.

[18] JEPSEN, S. The economic foundation on the ultrafiltration of milk. Nordeuropask Mejeri-tiosskrift, v. 11-12, p. 413-416. 1974.

[19] KOSIKOWSKI, F.V. Cheese and fermented milk foods. $3^{\text {rd }}$ ed. Ann Arbor MI: Edwards Bros. 1982.

[20] KOSIKOWSKI, F.V. New cheese making procedures utilizing ultrafiltration. Food Technology, v. 40, n. 6 , p. 71-77. 1986.
[21] LAWRENCE, R.C.; CREAMER, L.K.; GILLES, J. Texture development during cheese ripening. Journal of Dairy Science, v. 70, p. 1748-1760. 1987.

[22] LELIEVRE, J.; LAWRENCE, R.C. Manufacture of cheeses from milk concentrated by ultrafiltration. Journal of Dairy Research v. 55, n. 3, p. 465-478. 1988.

[23] MADSEN, J.S.; QVIST, K.B. The effect of added proteolytic enzymes on meltability of Mozzarella manufactured by ultrafiltration. Le Lait, v. 78, n. 2, p. 259. 1998.

[24] MAHAUT, M.; MAUBOIS, J.L. Transformation du lait en fromage grace a lémploi de lúltrafitration sur membrane. Rennes, France, Apostila I.N.R.A. 1985.

[25] MAUBois, J.L.; MOCQUOT, G.; VASsAL, L. "Procédé de traitment du lait et de sous-produits laitiers". Patent Française 2.052.121, Paris, France, 272. 1969.

[26] NIELSEN, P. Cheese production by ultrafiltration. Scandinavian Dairy Industry, n.1, p. 34-35. 1987.

[27] RUDAN, M.A.; BARBANO, D.M. A model of Mozzarella cheese melting and browning during pizza baking. Journal of Dairy Science, v. 81, n. 8, p. 2312-2319, 1998.

[28] SANCHEZ, V.A.A.G. Evolução de ácidos graxos e do perfil da textura durante a maturação de queijo Prato. 2000, 116p. Mestrado. Tecnologia Bioquímico-Farmacêutica, Universidade de São Paulo (USP).

[29] SCHIFTAN, T.Z.; KOMATSU, I. Estudo sobre a composição do queijo Prato consumido na cidade de São Paulo. Revista do Instituto de Laticínios Cândido Tostes, v. 35, n. 207, p. 33-38. 1980.

[30] SOUZA, E.A. Tecnologia da fabricação de queijos. Ed. da Revista do Instituto de Laticínios Cândido Tostes. 1960, 116p.

[31] SPANGLER, P.L.; JENSEN, L.A.; AMUNDSON, C.H.; OLSON, N.F.; HILL, C.G. Gouda cheese made from ultrafiltered milk effects of concentration factor, rennet concentration, and coagulation temperature. Journal of Dairy Science, v. 73, p. 1420-1428. 1990.

[32]TUNICK, M.H.; MALIN, E.L., SMITH, P.W.; HOLSINGER, V.H. Proteolysis and rheology of low fat and full fat Mozzarella cheese prepared from homogenized milk. Journal of Dairy Science, v. 76, p. 3621-3628. 1993.

\section{6 - AGRADECIMENTOS}

Os autores agradecem ao PIBIC-CNPq-SAE-UNICAMP e ao CNPq (bolsas de iniciação científica e de doutorado) e à FAPESP (Auxilio pesquisa 00/14079-8). 